Çukurova Üniversitesi Mühendislik Mimarlık Fakültesi Dergisi, 32(3), ss. 155-163, Eylül 2017

\title{
Faz Değiştirme ile Isı Depolamada Kullanılan Parafin-Grafit, Parafin- Kanatçık ve Saf Parafinli Yapıların Performans Analizi
}

\author{
Mohammad AZARÍFAR ${ }^{1}$, S. Kazım SÖMEK ${ }^{2}$, Nazlı DÖNMEZER ${ }^{* 3}$ \\ ${ }^{1}$ Orta Doğu Teknik Üniversitesi, Mühendislik Fakültesi, Makina Mühendisliği Bölümü, Ankara \\ ${ }^{2}$ Orta Doğu Teknik Üniversitesi, Mühendislik Fakültesi, Mikro Nano Teknoloji Bölümü, Ankara \\ ${ }^{3}$ Boğaziçi Üniversitesi, Mühendislik Fakültesi, Makina Mühendisliği Bölümü, İstanbul
}

Geliş tarihi: 11.01.2017

Kabul tarihi: 25.09.2017

Öz

Isıl enerjiyi depolamada Faz Değiştiren Maddelerin (FDM) kullanımı en verimli yöntemlerden biridir. Değişken aralıklı erime/katılaşma sıcaklığına ve ortalama 1sı depolama yoğunluğuna sahip ticari parafin 1sıl enerji depolamada en çok incelenen FDM'lerin başında gelir. Parafin FDM'ler yüksek 1sı depolama kapasitelerine rağmen düşük 1sı iletkenliklerinden dolayı sistemlerin 1sıl şarj/deşarj hızını belirgin olarak sınırlamaktadır. Parafinin 1sıl iletkenliğini iyileştirme amaçlı kanatçık ve parafin-grafit yapılar kullanılmaktadır. Bu çalışmada isıl iletkenlikleri geliştirilmiş parafin-grafit, parafin-kanatçık ile saf parafinli iki boyutlu yapılar 1sıl deşarj anında modellenerek ssıl performansları bakımından birbirleriyle karşılaştııılmıştır. Bu karşılaştırmada yapıların zamana bağlı sıcaklık dağılımları, deşarj ettikleri toplam 1Sı miktarı ve faz değiştirme hızları belirleyici faktörler olarak kullanılmıştır. Sonuçlar, parafin-kanatçık yapıların 1sıl performanslarının, yüksek 1sı deşarj hızı ve 1S1 depolama kapasiteleri birlikte düşünüldüğünde, parafin-grafit ve saf parafin yapılarla karşılaştırıldı̆̆ında daha gelişmiş olduğunu göstermektedir.

Anahtar Kelimeler: Parafin, Grafit, Metal kanatçık, Faz değiştiren madde (FDM)

\section{Performance Analysis of Paraffin-Graphite, Paraffin-Fin and Pure Paraffin Structures Used in Phase Change Energy Storage}

\begin{abstract}
Usage of Phase Change Materials (PCM) for storage of thermal energy is one of the most efficient methods to store thermal energy. The commercial paraffin, with a wide range of melting and solidification temperatures as well as moderate thermal storage densities, has been one of the most studied PCMs for thermal energy storage. Although the thermal storage capacity of paraffin PCMs are high, their low thermal conductivity limits the thermal charging/discharging rates considerably. The thermal conductivity of paraffin is enhanced by finned and paraffin-graphite structures. In this study, pure paraffin and thermally enhanced paraffin-graphite and paraffin-fin two-dimensional structures during thermal discharge are modeled. After modeling their thermal responses are compared with each other. The transient temperature distribution, total energy discharged and the rate of phase change are used as indicators in this comparison. The results show, considering both the thermal discharge rate and the
\end{abstract}

"Sorumlu yazar (Corresponding author): Nazlı DÖNMEZER, nazli.donmezer@boun.edu.tr 
Faz Değiştirme ile Isı Depolamada Kullanılan Parafin-Grafit, Parafin-Kanatçık ve Saf Parafinli Yapıların Performans Analizi

storage capacities, that the thermal performance of paraffin-fin structures are superior to paraffin-graphite and the pure-paraffin structures.

Keywords: Paraffin, Graphite, Metal fin, Phase change material (PCM)

\section{GíRİş}

Güneş, rüzgâr, vb. pek çok enerji kaynağı mevsimsel, günlük ve y1llık değişimlerden ötürü düzenli bir şekilde enerji üretememektedir. Enerjinin düzenli olarak üretilebildiği durumlarda ise enerjinin tüketiminde düzensizlikler görülebilmektedir. Düzenli enerji üretiminin ve tüketiminin problem olduğu uygulamalarda enerji depolama enerji kullanımı düzenleyerek kayıpları en aza indirdiğinden ötürü oldukça önem taşımaktadır. Bazı uygulamalar için bir kaç saat gibi kısa süreli enerji depolama yeterli olurken başka uygulamalarda birkaç aylık depolama gerekebilir [1]. Isıl enerji depolama artan enerjinin depolanmasında kullanılan yöntemlerden biridir ve 1s1 bu uygulamalarda duyulur ve/veya gizil 1sil formunda depolanır. Duyulur ve gizil 1sının 1sıl enerji depolama için birlikte kullanılmasında faz değişim malzemeleri (FDM) kullanımı 1940'larda başlasa da, bu malzemelerin popülerliği 1970'lerin sonlarında petrol ambargosu ile başlayan enerji krizi ile artmıştır [2]. Öncelikli olarak güneş enerjisinin depolanmasında kullanılan FDM'ler sonraları enerji dağıtım şebekelerinin performans ve güvenilirliğini artırmış ve enerji tasarrufuna katkı yapmıştır [3].

Faz değişim malzemeleri organik, inorganik ve ötektik olmak üzere üç ana gruba ayrılır [3]. Kullanım alanına göre FDM'lerin avantaj ve dezavantajları vardır. Organik bir FDM türü olan parafin, gizil 1S1 miktarının istenilen aralıkta olması, kimyasal kararlılığı, faz ayrımının olmaması ve ticari olarak bulunurluğu sebebiyle enerji depolamada kullanılan FDM'lerin başında gelmektedir $[1,4,5]$. Bütün bu olumlu özelliklerin yanı sıra parafin; 1sıl enerji depolamada etkinliği azaltacak düşük 1sı iletkenliğine sahiptir [1]. Parafinin düşük 1s1 iletkenliği, 1s1 depolamada kullanılan parafinli sistemlerin 1sıl şarj/deşarj hızını belirgin olarak sınırlamaktadır. Parafinin 1sı iletkenliğini artırmak için parafinin metal köpükler ve kanatçı [6,7] gibi yapılarla beraber kullanılması önerilmiştir.

Bir başka iyileştirme yöntemi ise parafin ile 1sıl iletkenliği yüksek malzemelerin birleştirilmesi ile elde edilen kompozit malzemelerin parafin yerine kullanılmasıdır [8-15]. Parafin-grafit kompozit yapılar 1sı iletkenliği iyileştirilmiş kompozit FDM'lere örnek olarak gösterilebilir. Daha önce farklı grafit yoğunluğu kullanılarak oluşturulan malzemelerin isıl iletkenliklerinin saf parafinden 28-40 kat fazla olduğu deneysel ve modelleme yöntemleri ile kanıtlanmıştır [12-14].

Parafin-grafit kompozit malzemeler genleştirilebilir grafit malzemelerin genleştirilmesi sonucu oluşan mikron boyutlu hava boşluklarına sahip köpük yapının içerisine eritilmiş parafin zerk ederek hazırlanır. Hazırlanması sırasında grafit yoğunluğu malzemenin özelliklerini değiștirmek üzere değiştirilebilir. Genleştirilmiş grafit soğuk sıkıştırma tekniği kullanılarak baryum hidroksit gibi inorganik FDM'ler ile birleştirildiğinde parafin-grafit yapılardan daha yüksek 1s1 depolayabilse de hem yüksek sıcaklıklardaki dayanıksızlığı hem de düşük 1sı iletkenliği nedeniyle tercih edilmemektedir [12].

Is1 iletkenliğini arttırmada parafin-grafit yapıların kullanımı uygun yapıda grafit üreten firmaların artışı ve bu tür malzeme oluşturmada yapılan araştırmalar ile yaygınlaşmaktadır. Buna rağmen kullanımı daha eskiye dayanan metal kanatçık uygulamaları da daha verimli kanatçık yapıların geliştirilmesi ve sistemlere dâhil edilmesinde yapılan geliştirmeler sayesinde halen popülerliğini korumaktadır. Daha önceki çalışmalarda parafin ve parafin-grafit [12-14] ile parafin ve parafinkanatçık yapılar kendi aralarında karşılaştırılmıştır. Isıl iletkenlikte parafin-grafit ve parafin-kanatçık yapıların saf parafinden iyi olduğu kanıtlansa da bu iki yöntemi birbirleriyle ve saf parafinle karşılaştırılması üzerine bir çalışma 
gözlenmemiştir. Literatürdeki bu eksiği doldurmak dolayısıyla parafin-grafitin parafin-kanatçık yapılara göre performansını anlamak ileride tasarlanacak enerji depolama sistemlerinde kullanılacak malzemelerin belirlenebilmesi için gereklidir.

$\mathrm{Bu}$ çalışmada saf parafin, parafin-grafit ve kanatçık ile iyileştirilmiş parafin çözümlerin karşılaştırmalı olarak performans analizinin faz değişiminin dâhil edildiği zamana bağlı 1 sıl benzetimler aracılığıyla yapılması hedeflenmiştir. Is1l analizler sonucunda saf parafin, parafinkanatçık ve parafin-grafit yapıların zamana bağlı sıcaklık dağılımları, toplam enerjilerindeki değişimleri ve faz değiştirme oranları elde edilerek, karşılaştırmaları yapılmıştır.

\section{METOT}

Saf parafin, parafin-kanatçık ve parafin-grafit içeren yapıların ısıl performans analizini yapmak üzere uzun silindirik bir su 1sitma/soğutma ünitesindeki 1s1 iletimi COMSOL Multiphysics kullanılarak modellenmiştir. Kullanılan silindirik 1S1 depolama ünitesinin kesiti Şekil 1(a)'da gösterilmektedir. Ünite iç içe geçmiş eş merkezli iki borudan oluşmaktadır. Yüzey sicaklığı $\mathrm{T}_{\mathrm{i}}=50{ }^{\circ} \mathrm{C}$ ve çapı $\mathrm{D}_{\mathrm{i}}=60 \mathrm{~mm}$ olan iç $1 \mathrm{~s}$ transferi borusu çap1 $\mathrm{D}_{\mathrm{o}}=230 \mathrm{~mm}$ olan yalıtılmış $1 \mathrm{~s} 1$ depolama borusunun içerisine yerleştirilmiştir. Is1 depolamada kullanılan geometri daha önce yoğunlaştırılmış güneş enerjisi 1sısının depolanmasi ve su isitmada kullanılmasının araştırıldığı çalışmadan alınmıştır [9]. Isı depolama borusunun iç kısımları Şekil 1(a)'da gösterildiği gibi saf parafin veya parafin temelli FDM ile doldurulmuştur. $\mathrm{Bu}$ çalışma için seçilen parafin çeşidi yüksek 1sı depolama kapasitesi ve uygun erime sıcaklığından dolayı Rubitherm RT65'dir. Çalışmada FDM olarak saf RT65 parafinin yanı sıra 1sıl iletkenliği bakımından geliştirilmiş parafin-grafit yapı da kullanılmıştır. Son olarak 1S1 depolama borusu yine isıl iletkenliği artırmak üzere kanatçık yapılar ile zenginleştirilmiş.

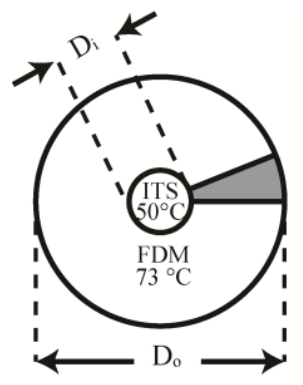

(a)

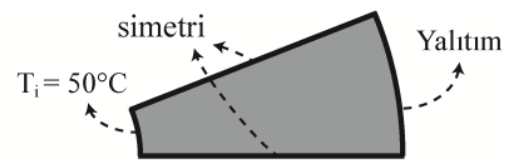

(b)

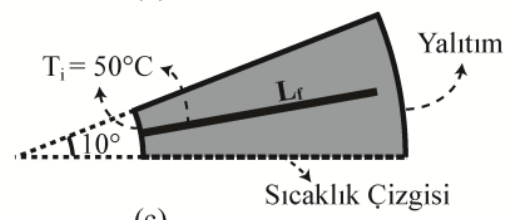

(c)

Şekil 1. (a) Isı depolama ünitesinin kesiti. (Gri alan simetri koşulları göze alınarak modellenmesi yeterli bulunan örnek alanı temsil eder) (b) Saf parafin ve parafin-grafit (c) parafin-kanatçık yapıların analizinde kullanılan örnek alanlar

Parafin-kanatçık yapıda 1S1 transfer yüzeyini arttırmak üzere $10^{\circ}$ aralıklarla toplam $\mathrm{N}_{\mathrm{f}}=36$ adet $\mathrm{L}_{\mathrm{f}}=80 \mathrm{~mm}$ uzunluğa sahip ince, uzunlamasına kanatçık yerleştirilmiştir geri kalan kısımlar ise RT65 saf parafin ile doldurulmuştur. Kullanılan kanatçıkların kalınlıkları ihmal edilebilir düzeyde olduğundan 1S1 depolama borusu içinde parafin hacmi ve kütlesi sabit tutulmuştur. Yine aynı nedenden ötürü kanatçıklar içindeki 1sı iletimi ihmal edilmiş, kanatçık sıcaklığı 1sı depolama borusunun iç çeper sicaklığına $\left(\mathrm{T}_{\mathrm{i}}=50{ }^{\circ} \mathrm{C}\right)$ eşit sayılmıştır. Ayrıca, 1sı depolama ünitesinin uzunluğu kesitine göre büyük olduğu için ünitenin uzunluğu boyunca oluşan isı transferi ihmal edilmiş ve iki boyutlu benzetimler kullanılmıştır. Son olarak problemin kesit simetrisi de kullanılarak, problem Şekil 1(b) ve (c)'de gösterilen küçük ve analizi kolay örnek hacimlere indirgenmiştir. 
Parafin-grafit yapı için geometrik bir değişiklik yapılmayıp Şekil 1(b)'de kullanılan yapı hem saf parafin hem de parafin-grafit yapıların analizi için kullanılmıştır. Şekil 1(c)'de gösterilen yapı ise parafin-kanatçık yapının analizinde kullanılmıştır.
Çalışmada kullanılan saf parafin (RT65) ve parafin-grafit malzemelerin malzeme özellikleri sirasiyla üretici verileri ve RT65 tabanlı parafingrafit malzemenin araştırıldığı çalışma [12] temel alınarak elde edilmiş, Çizelge 1'de gösterilmiştir.

Çizelge 1. Saf parafin ve grafit-parafin malzemenin özellikleri

\begin{tabular}{|l|c|c|c|c|c|c|}
\hline & $\begin{array}{c}\text { Erime } \\
\text { Sicaklığ } \\
\mathrm{T}_{\mathrm{M}}\left({ }^{\circ} \mathrm{C}\right)\end{array}$ & $\begin{array}{c}\text { Erime } \\
\text { Aralığ1 } \\
\Delta \mathrm{T}_{\mathrm{M}}\left({ }^{\circ} \mathrm{C}\right)\end{array}$ & $\begin{array}{c}\text { Isı İletkenlik } \\
\text { Katsay1s1 } \\
k(\mathrm{~W} /(\mathrm{m} \cdot \mathrm{K})\end{array}$ & $\begin{array}{c}\text { Öz Is1 } \\
\text { Kapasitesi } \\
c_{P}(\mathrm{~J} /(\mathrm{kg} \cdot \mathrm{K})\end{array}$ & Gizil Is1 & Öz kütle \\
\hline $\begin{array}{l}\text { Saf Parafin } \\
\left(\mathrm{RT} 65^{*}\right)\end{array}$ & 65 & 11 & 0,2 & 2000 & 155000 & $\begin{array}{c}780(\mathrm{Jg}) \\
880(\mathrm{~kat} 1)\end{array}$ \\
\hline $\begin{array}{l}\text { Parafin- } \\
\text { Grafit [12] }\end{array}$ & 65 & 4 & 15 & 1800 & 150000 & $\begin{array}{c}590(\mathrm{~s} 1 \mathrm{v} 1) \\
610(\mathrm{~kat} 1)\end{array}$ \\
\hline
\end{tabular}

* Rubitherm RT65 üretici verisi

COMSOL Multiphysics 1s1l benzetimleri kullanılarak modellenen Şekil 1(b) ve (c)'deki örnek alanların iç yüzeyi (iç boruda bulunan 1sı taşıyıcı akışkanı temsilen) ve Şekil 1(c)deki kanatçık yüzeyi sabit $\mathrm{T}_{\mathrm{i}}=50{ }^{\circ} \mathrm{C}$, dış ve yan yüzeyleri ise yalıtılmış/simetri yüzeyleri olarak tanımlanmıştır. FDM ilk olarak sıvı halde $\mathrm{T}_{0}=73^{\circ} \mathrm{C}$ 'de bulunmaktadır. FDM sıcaklığı daha düşük olan ısı taşıyıcı akışkan ile etkileşime geçerek önce sıcaklık değişimi daha sonra donma daha sonra tekrar sıcaklık değişimi aşamalarından geçer. Isıl benzetimde bu üç farklı aşamayı temsil etmek ve FDM'nin faz değişimi sırasında gizil ısı depolamasını tanımlamak üzere farklı aşamalarda Eşitlik 1'deki öz ısı kapasiteleri, $c_{P}$, kullanılmıştır. Burada kullanılan varsayım malzemenin donma öncesi ve sonrasında öz 1S1 kapasitesini koruduğudur. Donma esnasında gizil ısının depolanması için bir erime aralığı, $\Delta \mathrm{T}_{\mathrm{M}}$, tanımlamak kullanılan bir yöntemdir.

$$
c_{P}=\left\{\begin{array}{lc}
c_{p} & T<\left(T_{M}-\frac{\Delta T_{M}}{2}\right) \\
c_{P}+l_{f} / \Delta T_{M} & \left(T_{M}-\frac{\Delta T_{M}}{2}\right)<T<\left(T_{M}+\frac{\Delta T_{M}}{2}\right) \\
c_{P} & \left(T_{M}+\frac{\Delta T_{M}}{2}\right)<\mathrm{T}
\end{array}\right.
$$

Bu modele göre öz 1S1 kapasitesi erime aralığında faz değişiminde gizil 1sı ile depolanan enerji kadar artırılır. Eşitlik 1'deki öz 1S1 kapasiteleri aynı zamanda sistemin toplam enerji seviyesinin hesabı için de kullanılmaktadır.

Aynı zamanda donmanın ne oranda gerçekleştiğini anlamak için de katı ve sıvı fazlara Eşitlik 2'deki gibi farklı öz kütleler tanımlamak yeterli olmaktadır. Saf-parafin için katı ve sıvı öz kütleleri değişiklik göstermektedir ve üretici verisi kullanılarak modellenmiştir. Parafin-grafit yapıda erime sırasında daha az bir öz kütle değişimi olmaktadır. Bunun nedeni grafit yapının faz değiştirmemesi sadece parafinin donmasıdır. Buna rağmen donma oranını tanımlamak üzere katı ve sıvı için Çizelge 1'deki değerler tanımlanmıştır. Donma öncesinde ve sonrasinda öz kütle Eşitlik 2'deki gibidir.

$$
\rho= \begin{cases}\rho_{l} & T \leq T_{M} \\ \rho_{s} & T_{M}<T\end{cases}
$$

İstenilen anda sistemin ortalama öz kütlesi bulunarak ve Eşitlik 2'deki öz kütleler kullanılarak sistemde donma miktarı bulunabilmektedir. Isıl benzetimler örnek hacimde sabit sıcaklığa gelinene kadar devam ettirilmiştir. Benzetimler sonucunda 
elde edilen sonuçlar bir sonraki kısımda gösterilmektedir.

\section{SONUÇLAR}

\subsection{Sıcaklık Analizi}

Parafin-grafit, parafin-kanatçık ve saf parafin FDM kullanılan Şekil 1(b) ve (c)'de gösterilen örnek alanlar modellenerek zamana bağlı sicaklık dağılımları elde edilmiştir. Şekil 2'de bu yapılarda 20,40 ve 60 . dakikalarda oluşan sicaklık dağılımları verilmektedir. $\mathrm{Bu}$ dağılımlara bakıldığında Şekil 2(a) ve (b)'deki kanatçık olmayan yapılarda, ısı dağılımı dolayısıyla da faz değişimi iç çeperden diş çepere doğru düzenli bir şekilde olmaktadır. Buna rağmen Şekil 2(b)'de gösterilen, kanatçık kullanılan yapıda sıcaklık dağılımı ve faz değişimi sadece iç çeperden dış çepere doğru olmamakta, kanatçık yüzeylerinden dışarıya doğru da olmaktadır. Bunda kanatçık yapının çok ince ve yüksek ısı transferi katsayısına sahip olduğunu varsaymaktan doğan sabit sıcaklık sınır koşulu büyük rol oynamaktadır. Kanatçığın doğrudan temasta bulunduğu FDM'nin sicaklığını değiştirmesi ve faz değişimini başlatması kanatçıkla yapıların faz değiştirme hızını arttırmakta başarılı olduğunu göstermektedir.

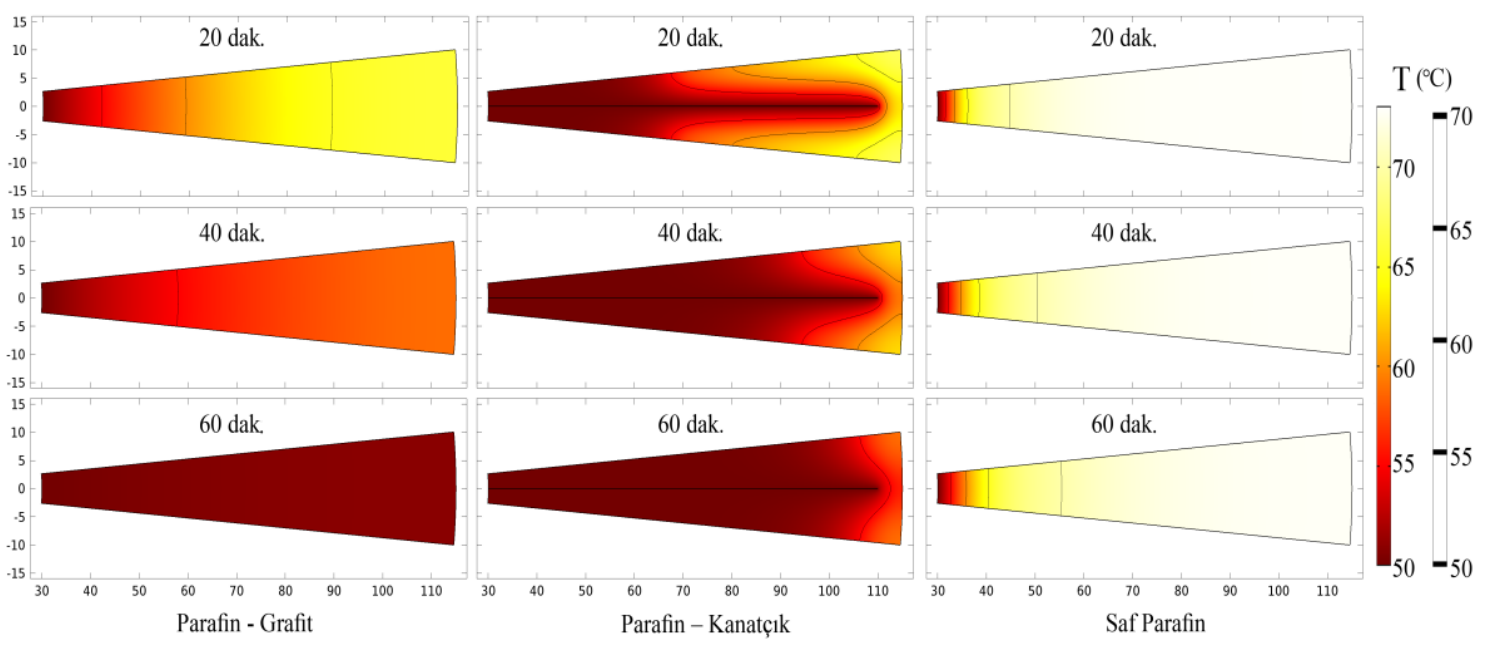

(a)

(b)

(c)

Şekil 2. (a) Parafin-Grafit (b) Parafin-Kanatçık ve (c) Saf Parafin ısı depolama ünitelerindeki 20, 40 ve 60 dakikalardaki sıcaklık grafikleri

Ayrıca Şekil 2'de 40. dakikada farklı yapıların sıcaklık dağılımlarına bakıldığında parafin-grafit ve parafin-kanatçık yapıların neredeyse tamamının sıcaklığının erime/donma sıcaklığı olan $\mathrm{T}_{\mathrm{M}}=65{ }^{\circ} \mathrm{C}$ altına düştüğü fakat saf-parafinli yapının büyük kısmının sıcaklığının erime sicaklığının üstünde olduğu görülebilmektedir. Bu saf-parafinli yapının büyük kısmının henüz donmasını tamamlayamadığını göstermektedir. Bunun nedeni, Çizelge 1'de verilen saf parafinin, parafin-grafit malzemeden neredeyse 30 kat düşük 1sı iletim katsayısıdır. Düşük 1Sı iletim katsayısı ısının parafin içerisinde verimli bir şekilde dağılmasını engelleyerek soğumayı yavaşlatır. Isı transferi modülündeki sıcaklık değişimini daha iyi anlamak için 1s1 depolama alanı içerisinde 1sı transferi sıvısını olduğu iç çeperden yalıtılmış dış yüzeye kadar olan sıcaklık dağılımları Şekil 1'de gösterilen sıcaklık çizgisi boyunca farklı zamanlarda elde edilmiştir. Elde edilen çizgisel sıcaklık dağılımları Şekil 3'de verilmiştir. Sıcaklık çizgisi kanatçık yapıda komşu kanatçıkların tam ortasından geçecek şekilde konumlandırıldığı için kanatçık yapılarda 1 s 1 transferinin en yavaş olduğu bölgelere denk gelmektedir. 

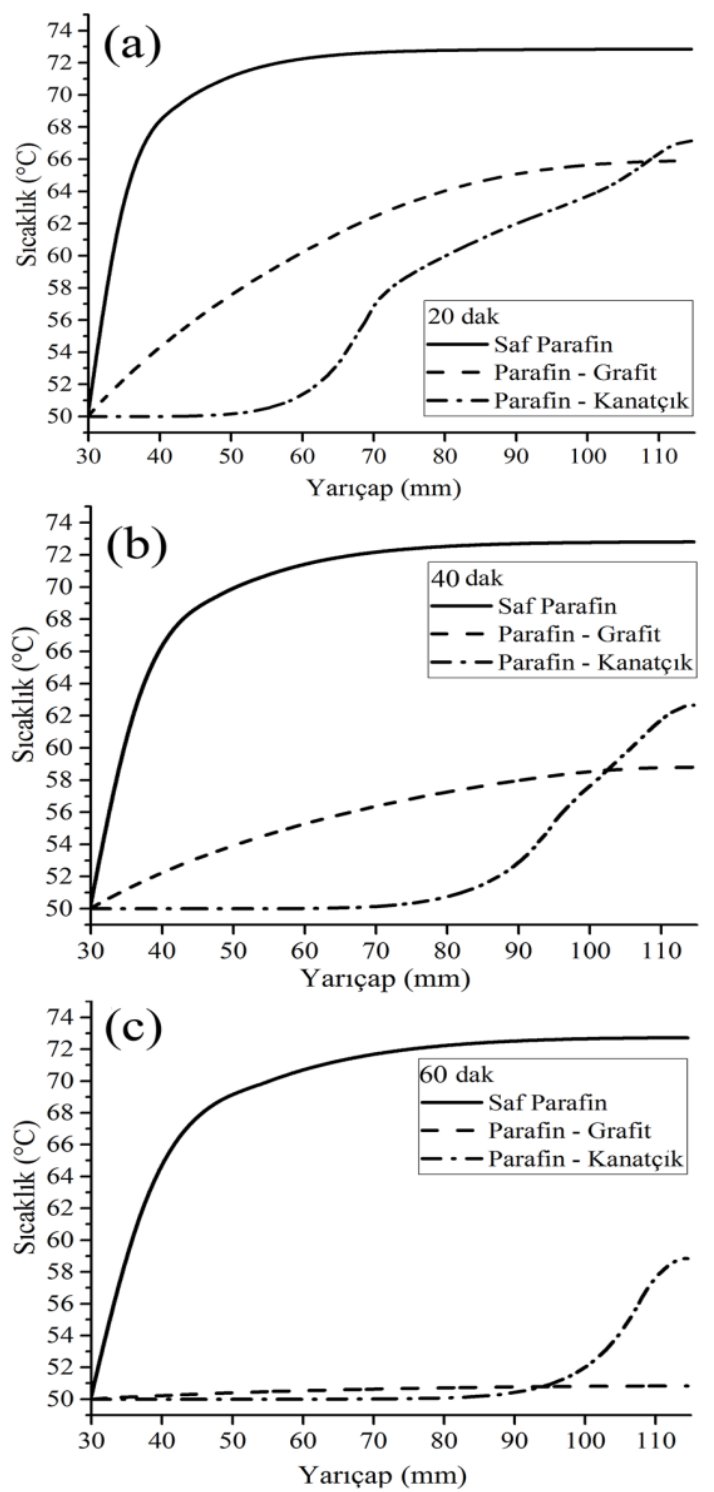

Şekil 3. (a) 20 (b) 40 ve (c) 60'inci dakikalarda saf-parafin, parafin-grafit ve parafinkanatçı FDM kullanılan 1sı transfer modülünde yarıçap boyunca sıcaklık çizgisi üzerindeki sıcaklık değişimi

Şekil 3'de görüldüğü üzere saf parafinli yapıda sıcaklık çoğu bölgede uzun sure sabit kalmaktadır ve çok yavaş azalmaktadır. Buna rağmen Şekil 3(c)'de görüldüğü üzere, parafin-grafit yapıda birinci saatin sonuna gelindiğinde mümkün olan sicaklık değişiminin neredeyse tamamı geçirilmiş tüm parafin-grafit yapı ITS'nın sıcaklığına $\left(50^{\circ} \mathrm{C}\right)$ ulaşmıştır.

Kanatçık yapıda ise kanatçıklardan gelen ısı iletimi etkisiyle daha karmaşık bir sıcaklık dağılımı görülmektedir. Aslında ilk 40 dakikada parafinkanatçık yapının sıcaklık değişimi, Şekil 3(b) ve (c)'den de anlaşılacağı gibi çok hızlı olsa da bir saate yaklaşıldığında kanatçık etkisi azalır ve ısının kanatçıklardan uzak olan köşe noktalardan transferi önem taşımaya başlar. Bunun sonucunda 1S1 transferi yavaşlamaya başlar. Parafin-grafit yapıda 1sı iletkenliği her yerde yüksek olduğu için zamanla 1S1 transferinin yavaşlaması parafinkanatçık yapıdaki kadar fazla olmaz ve bir süre sonra parafin-grafit yapı parafin-kanatçık yapı ile aynı performansa ulaşır ve onu geçer. Bunun sonucu olarak, ortalama bir saat gibi bir sürede parafin-grafit yapının katılaşması tamamlansa da parafin-kanatçık yapı bu sırada hala donmasını tamamen tamamlayamamış olur.

\subsection{Enerji Analizi}

Is1 depolama ünitesinin soğuma ve donma ile enerjiyi ITS'na aktarma hızını, bir başka değişle deşarj hızını anlamak üzere 1sı depolama modülünün toplam enerji seviyesinin zamana bağlı değişimleri Eşitlik 1'de verilen öz 1sı kapasiteleri kullanılarak elde edilmiştir. Bu değerler Şekil 4'de gösterilmektedir.

Şekil 4'de gösterildiği üzere saf parafinin toplam enerji seviyesinde ilk bir saatlik dilimde ciddi bir düşüş görülmemektedir. $\mathrm{Bu}$ saf-parafinin bir saatlik süre içerisinde enerji deşarjının yeterli seviyede olmadığını ve saf parafinli yapıda depolanan enerjinin deşarjı için daha fazla beklenilmesi gerektiğini gösterir. Buna rağmen, bir saatin sonunda parafin-kanatçık ve parafin-grafit yapılarda tatmin edici bir 1S1 deşarjı olduğu görülmektedir. Parafin-kanatçık yapının toplam enerji seviyesindeki azalmaya bakıldığında, deşarj hızının ilk başlarda çok yüksek olduğu görülmektedir. Bu sonuç kanatçıkların başlarda daha etkin olduğunu destekler niteliktedir. Parafin-grafit yap1 ise 50 dakika sonunda maksimum deşarj seviyesine ulaşmıştır ve görevini tamamlamıştır. 


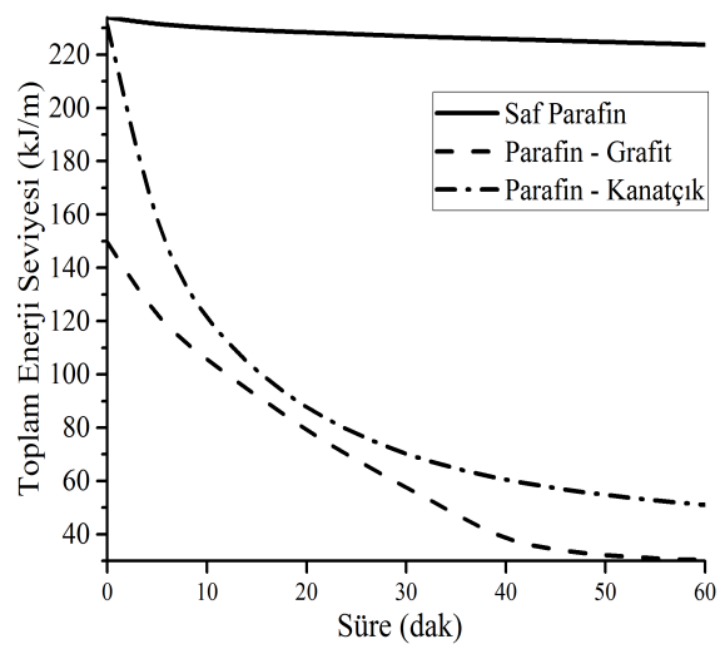

Şekil 4. Farklı sürelerde 1Sı depolama modülü içerisinde depolanan toplam enerji seviyesi

Burada önemli nokta Şekil 4'de görüldüğü üzere, saf-parafin ve parafin-kanatçık yapıların başlangıç enerji seviyesinin parafin-grafite göre daha fazla olmasıdır. Bu farklılığın nedeni aynı hacme sahip parafin-grafit yapının içerdiği parafin kütlesinin saf parafin içeren yapınınkinden az oluşudur. Parafin-grafit yapının bir kısmı 1sıyı depolama özelliği ile bilinen parafinden oluşsa da bir kısmı grafit malzeme ile dolu olduğundan malzemenin hacimsel öz 1sı kapasitesi Çizelge 1'de görüldüğü üzere saf parafinden düşüktür. Bu nedenden ötürü bütün yapilarda modellemeye FDM'nin başlangıçta sabit sıcaklıkta $\left(\mathrm{T}_{0}=73{ }^{\circ} \mathrm{C}\right)$ olduğu varsayımı ile başlandığında, yapıların başlangıçta depoladıkları isıl enerji farklılaşmaktadır. Depolanan 1sı miktarını artırmak için daha büyük hacimli yapılar kullanılması da 1s1 iletiminin olumlu etkilerini azaltacaktır. Parafin-kanatçık yapıda kanatçıkların ihmal edilebilir incelikte olduğu varsayımından dolayı aynı hacimdeki parafin miktarı değişmediğinden bu sorun görülmemektedir.

Özetle parafin-grafit yapılar en hızlı deşarj süresine sahip olsa da aynı sıcaklıkta hacim başına depolayabildiği enerji saf parafin ve parafinkanatçık yapılardan daha düşük olacaktır. Bu da parafin-kanatçık yapıların özellikle son etapta performansının yavaşlamasına rağmen depolayabildiği 1sı miktarı ve hızlı deşarj özellikleri açısından en uygun yapı olduğunu göstermektedir.

Son olarak saf parafin, parafin-grafit ve parafinkanatçık yapılar bulunduran 1S1 depolama ünitelerinde zamana bağlı katılaşma yüzdeleri Şekil 5'de gösterilmektedir. Katılaşma yüzdesinin hesaplanması daha öncede bahsedildiği üzere Eşitlik 2'deki öz kütle değişimleri kullanılarak gerçekleştirilir. Şekil 5'de görüldüğü üzere parafin-kanatçık yapılarda toplam katılaşma yüzdesi ilk zamanlarda oldukça yüksektir. Bir sure sonra kanatçıkların etkisinin azalmasıyla kanatçıklara uzak köşe noktalarda donma zorlaşır ve parafin-grafit yapıdaki katılaşma yüzdesi parafin-kanatçık yapınınkine 30 dakikadan sonra yaklaşır. Daha önce bahsedildiği üzere 1sıl modellemede gizil ısının etkisini erime aralığı $\left(\Delta \mathrm{T}_{\mathrm{M}}\right)$ tanımlayarak modele dâhil ettiğimiz için katılaşma saf parafinli ve parafin-kanatçık yapılar için $\Delta \mathrm{T}_{\mathrm{M}}=11^{\circ} \mathrm{C}^{\prime}$ lik bir aralıkta sabit artışlı gerçekleşmektedir. $\mathrm{Bu}$ varsayımlar nedeniyle gerçek katılaşma yüzdesi Şekil 5'de verilen değerlerden farklılık gösterebilse de Şekil 5 katılaşma yüzdesinin değişimi ile ilgili yeterli bilgiyi vermektedir.

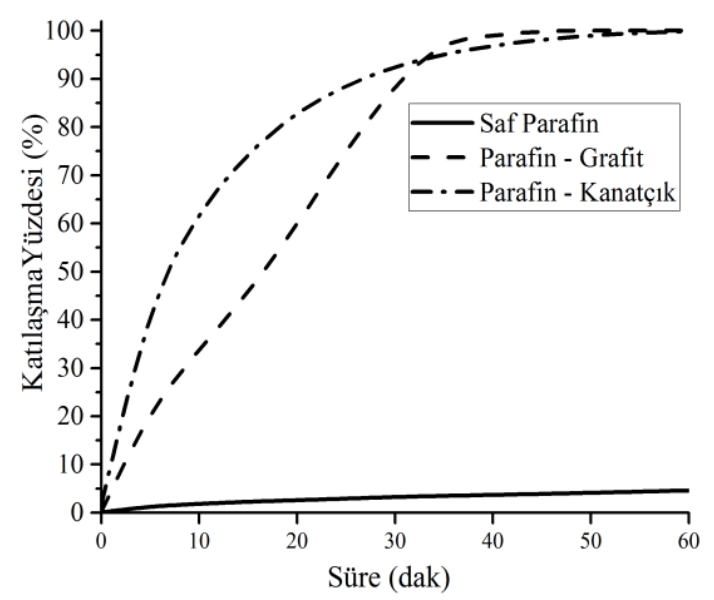

Şekil 5. Saf parafin, parafin-grafit ve parafinkanatçık yapılarda zamana bağlı katılaşma yüzdesi

Sonuç olarak aynı hacme sahip ısı depolama alanı için saf-parafin, parafin-grafit, parafin-kanatçık 
Faz Değiştirme ile Isı Depolamada Kullanılan Parafin-Grafit, Parafin-Kanatçık ve Saf Parafinli Yapıların Performans Analizi

yapıların üçünün de birlikte karşılaştırıldığı bu çalışma ile:

- Parafin-kanatçık yapının iSı transferini iyileştirerek donma ve deşarj hızının artmasını sağladığı,

- Benzer bir iyileştirme parafin-grafit yapıda görülse de parafin-kanatçık yapının aynı hacimde daha fazla 1s depolayabildiği,

anlaşılmıştır. $\mathrm{Bu}$ nedenle çalışmada kullanılan şekilde parafin-kanatçık yapının depolama amaçlı kullanılmada en uygun seçenek olduğu görülmektedir. Farklı uygulamalar için kanatçık sayısını ve uzunluğunu değiştirmek ile benzer performanslar elde etmek mümkün olacaktır. Öte yandan parafin-grafit yapıların isıl özelliklerini değiştirmek grafit öz kütlesini değiştirmek ile mümkün olsa da bu konuda yapılacak değişiklikler daha sinırlıdir.

\section{TEŞEKKÜR}

$\mathrm{Bu}$ çalışmanın başında parafin-grafit yapılar ile ilgili bilgiler ve yardımlarından ötürü Anne Mallow’a teşekkürlerimizi sunarız.

\section{KAYNAKLAR}

1. Farid, M.M., Khudhair, A.M., Razack, S.A.K., Al-Hallaj., S., 2004. A Review on Phase Change Energy Storage: Materials and Applications, Energy Conversion and Management, vol. 45, no. 9-10, 1597-1615.

2. Sharma, S.D., Kitano, H., Sagara, K., 2004. Phase Change Materials for Low Temperature Solar Thermal Applications, Res. Rep. Fac. Eng. Mie Univ., vol. 29, 31-64.

3. Rathod, M.K., Banerjee, J., 2013. Thermal Stability of Phase Change Materials Used in Latent Heat Energy Storage Systems: A Review, Renewable and Sustainable Energy Reviews, vol. 18, 246-258.

4. Sari, A., Karaipekli, A., 2008. Preparation, Thermal Properties and Thermal Reliability of Capric Acid/expanded Perlite Composite for Thermal Energy Storage, Mater. Chem. Phys., vol. 109 , no. 2-3, 459-464.
5. Zalba, B., 2003. Review on Thermal Energy Storage with Phase Change: Materials, Heat Transfer Analysis and Applications, Appl. Therm. Eng., vol. 23, no. 3, 251-283.

6. Sciacovelli, A., Guelpa, E., Verda, V., 2014. Second Law Optimization of a PCM Based Latent Heat Thermal Energy Storage System with Tree Shaped Fins, Int. J. Thermodyn., vol. 17, no. 3, 127-136.

7. Sciacovelli, A., Gagliardi, F., and Verda, V., 2015. Maximization of Performance of a PCM Latent Heat Storage System with Innovative Fins, Appl. Energy, vol. 137, 707-715.

8. Nallusamy, N., Sampath, S., Velraj, R., 2006. Study on Performance of a Packed Bed Latent Heat Thermal Energy Storage Unit Integrated with Solar Water Heating System, J. Zhejiang Univ. Sci. A, vol. 7, no. 8,1422-1430.

9. Singh, D., Zhao, W., Yu, W., France, D.M., Kim, T., 2015. Analysis of a Graphite Foam$\mathrm{NaCl}$ Latent Heat Storage System for Supercritical $\mathrm{CO}_{2}$ Power Cycles for Concentrated Solar Power, Sol. Energy, vol. 118, 232-242.

10.Kim, T., France, D.M., Yu, W., Zhao, W., Singh, D., 2014. Heat Transfer Analysis of a Latent Heat Thermal Energy Storage System using Graphite Foam for Concentrated Solar Power, Sol. Energy, vol. 103, 438-447.

11. Moeini Sedeh, M., Khodadadi, J.M., 2013. Thermal Conductivity Improvement of Phase Change Materials/graphite Foam Composites, Carbon N. Y., vol. 60, 117-128.

12. Haillot, D., Py, X., Goetz, V., Benabdelkarim, M., 2008. Storage Composites for the Optimisation of Solar Water Heating Systems, Chem. Eng. Res. Des., vol. 86, no. 6, 612-617.

13. Haillot, D., Nepveu, F., Goetz, V., Py, X., Benabdelkarim, M., 2012. High Performance Storage Composite for the Enhancement of Solar Domestic Hot Water Systems. Part 2: Numerical System Analysis, Sol. Energy, vol. 86, no. 1, 64-77.

14. Haillot, D., Goetz, V., Py, X., Benabdelkarim, M., 2011. High Performance Storage Composite for the Enhancement of Solar Domestic Hot Water Systems. Part 1: Storage Material Investigation, Sol. Energy, vol. 85, no. 5, 1021-1027. 
15. Mills, A., Farid, M., Selman, J.R., Al-Hallaj, S., 2006. Thermal Conductivity Enhancement of Phase Change Materials Using a Graphite Matrix, Appl. Therm. Eng., vol. 26, no. 14-15, 1652-1661. 
